\title{
Towards the existentialist turn in IR: introduction to the symposium on anxiety
}

\author{
Jelena Subotić ${ }^{2} \cdot$ Filip Ejdus $^{1}$
}

Published online: 24 August 2021

(c) Springer Nature Limited 2021

\begin{abstract}
This symposium is a follow-up to the 2019 CEEISA/ISA conference 'International Relations in the Age of Anxiety' held at the Faculty of Political Science, University of Belgrade, Serbia, in June 2019. The central piece in the symposium is the keynote address by Bahar Rumelili on the untapped potential of existentialism in IR followed by highly engaged responses by Felix Berenskötter, Karl Gustafsson, Brent Steele and Andreja Zevnik. In this introduction we first describe the context in which we organised the conference and our motivations to choose the topic of the age of anxiety. We also reflect on how the global pandemic, which erupted in January 2020, made our topic more relevant than ever before. We then briefly introduce each piece and discuss what we see as the key questions they raise.
\end{abstract}

Keywords Age of anxiety $\cdot$ Crisis $\cdot$ Existentialism

What a difference two years make! This Symposium builds on the 2019 CEEISA/ ISA conference 'International Relations in the Age of Anxiety' held at the Faculty of Political Science, University of Belgrade, Serbia, in June 2019. When we designed the conference theme and invited Professor Bahar Rumelili to deliver the keynote address, our individual, collective, and global anxieties reflected a very different world and very different 'age of anxiety'. Our focus was on political anxiety produced by global democratic backsliding and the rise of authoritarianism in many previously considered 'consolidated democracies' - including many in Central and Eastern Europe and the Americas-North and South. Our political anxiety was further elevated because of the surprising strength and durability of populist

Filip Ejdus

filip.ejdus@fpn.bg.ac.rs

Jelena Subotić

jsubotic@gsu.edu

1 Faculty of Political Science, University of Belgrade, Belgrade, Serbia

2 Department of Political Science, Georgia State University, Atlanta, GA, USA 
and far-right movements, the long-lasting consequences of the 2007-2009 Great Recession and austerity measures that followed. We were anxious about the fractures inside the European Union, the looming crisis of Brexit, the renewed calls for 'land swaps' and 'territorial exchanges' in Southeastern Europe. One political crisis after another fueled a collective sense of dread.

Some of the anxieties and crises were structural-the future of NATO, the EU, or other long-standing international institutions and alliances, the demise of US hegemony and the uncertainty of the post-hegemonic international system. Other were crises of human security - the future for millions of Middle Eastern refugees who had escaped brutality and war only to arrive on the shores of Europe, where they were not wanted and were often further brutalised. And yet other anxieties were fuelled by the human cost of rising global inequality, environmental devastation, climate change, global retrenchment of the state, and its replacement by unregulated markets.

Two years later, how different and yet how same international anxieties are! The covid-19 pandemic engulfed the entire world just eight months after our conference ended. It exacerbated anxieties about the existing injustices and inequalities but then also heightened an even deeper, more existential set of anxieties-anxieties about health and death, about our children's futures, about constraints on movement and awareness of space, about economic precarity, and at its most existential levelabout the world changed forever and our unknown collective futures.

In this new, heightened state of global anxiety, our symposium is even more prescient than in 2019. Rumelili's intervention (2021) taking cues from existentialist thought, expands our understanding of anxiety as a recurring public mood along with its effects on international relations. Her essay, followed by highly engaged responses by Berenskötter (2021), Gustafsson (2021), Steele (2021) and Zevnik (2021), give us a theoretical grounding to process the different implications of our age of anxiety.

In the remainder of this introduction, we reflect on all five contributions and draw out three main questions about anxiety and the international: the relationship between anxiety and IR, between anxiety and levels of analysis, and between anxiety and emancipation. We address each relationship in turn.

The first set of questions around which the contributions to this symposium revolve are: What is anxiety? Is it yet another affect or experience, or is it in some ways constitutive of the political and of International Relations? What is the distinction between anxiety and fear, and how are the two connected?

Building on existentialist philosophy, which has been mostly ignored in IR, Rumelili construes anxiety as rooted in mortality and limits of knowledge and reflexivity. By drawing on Heidegger, Rumelili argues that anxiety is of fundamental importance as the basis of all other affective experiences. It is also a 'constitutive condition' for IR as it stems from the uncertainties of a Hobbesian world and the human desire to know it and control it. In contrast to fear, which is projected towards external objects such as migrants, terrorists, or any other threatening Others, anxiety stems from the subject's limits of knowledge and mortality. Similarly, for Steele, anxiety is a constitutive feature of international politics. In Steele's words, anxiety is even 'a deeper condition than the ordering principle of anarchy'. States may differ 
in how they manage anxiety through securitisation, routines, expertise or ideology, but whatever they do, 'anxiety isn't going anywhere'. International relations, both as a theory and practice, tend to be preoccupied with reducing anxiety, as Gustafsson writes. There are many ways to go about it, from creating routines or stable systems of meaning provided by expert knowledge or ideologies to the production of manageable objects of fear.

While anxiety is a constitutive feature of politics, when the mood of anxiety is heightened, what transpires is the age of anxiety, argues Rumelili. Berenskötter prefers to call them 'spaces of anxiety', as experiences of politics may vary even within one society. The mood of anxiety, Rumelili claims, does not cause but rather disposes people to be receptive to securitisation moves. It hence becomes a previously overlooked facilitating condition of securitisation processes. These insights are of potentially far-reaching relevance not only for securitisation theory but for critical security studies as a whole. They reveal a derivative function of securitisation, and shed light on its deep socio-psychological drivers, which may help us explain the well-known but poorly understood difficulties of overcoming the logic of security in world politics.

In his analysis, Steele zooms into these mechanisms in the case of US response to covid-19. Former US president Donald Trump's attempts to depict the virus as 'Chinese' is a textbook example of how anxiety is, more or less effectively, transformed into fear as a much more politically manageable public mood. Moreover, as Steele points out, routines and expert knowledge that societies turn to alleviate anxiety, transformed in the US and elsewhere into the very sources of anxiety. The US, in his view, at least under Trump, seemed to be comparatively poorly equipped to deal with anxiety successfully. While other countries may have given their experts more trust to steer their societies into new routines, the underlying anxiety depicted by Steele, as a constitutive condition of politics during pandemics, is all-pervasive and global.

Zevnik concurs with the assertion that anxiety is constitutive in her response, but she reaches that conclusion via Lacanian psychoanalysis. From this perspective, the existential conditions for anxiety are created as individuals lose their sense of wholeness with the appropriation of language. By internalising societal symbols, they become political subjects, but the price is a sense of alienation as these symbols are not of their own making. However, the sense of wholeness that they lost remains permanently their ultimate object of desire, which Lacan famously called objet petit $a$. The inability to restore this primary loss is creating permanent conditions for existential anxiety. Political structures are created to prevent the emergence of anxiety by constructing feared objects that ostensibly get in the way of satisfying the ultimate object of desire. However, when fantasies that keep this force at bay collapse, anxieties burst in and open the space for transformative political action.

This symposium also engaged with a question central to much International Relations scholarship — the problem of levels of analysis. Do relationships and patterns we identify in analysing world politics hold across units of analysis-across individuals, groups, and states? Or can features of individual behaviour, such as emotions, choices, or interests, be 'scaled up' to the level of groups and collectives (societies) and then further up to the level of a 'state'? Do states have feelings? Can states 
express anxiety? How would that anxiety manifest itself in ways that are observable and identifiable? Can states have biographies? Can they have pasts and futures? The issue of the level of analysis also brings up the point of universality of anxiety. Is anxiety a universal condition of human existence? And what about difference and subjects who are not anxious or are not all anxious about the same thing?

In her keynote address, Rumelili enters this debate by introducing the concept of state 'moods' that are brought to IR from Heidegger via Erik Ringmar. Mood, for Rumelili, is not a subjective mental state but an atmosphere or ways in which we are 'attuned to the world'. They are not affective states that we have but rather the ones in which we find ourselves in. She argues that anxiety can be better understood as a 'recurrent public mood' with its own sets of characteristics and parameters, only one of which is what we understand as 'anxiety'. In other words, anxiety does not affect world politics if it is not part of a broader public mood that contributes to and defines a particular form of anxiety that becomes broadly shared. Therefore, the public mood works at the level of a group and presents a meaningful social environment that shapes social responses to crises and can produce or be a hospitable moment for anxiety.

But as Berenskötter notes, the conceptualisation of public moods, while certainly useful, does not in Rumelili's account immediately explain how private, individual moods become public. Or is it the other way around? Berenskötter asks whether a shared, collective sense of anxiety emerges from some sense of grouped, collective accumulation of individual anxieties? Or is it an altogether independent process that should not be understood as a sum of its individual parts? For Berenskötter, then, the solution is to reverse somewhat the order of 'scaling up' and to, instead, 'scale down'- to conceptualise the individual, for example, a state leader, as a personification of collective biography, a collective sense of identity. Reconfigured this way, collective anxiety is something that is both producing a particular form of political agency and action personified in a state leader. It is also itself the product of a public mood, which, to a large extent, a state leader themselves has created-as, most recently, and most clearly, was the case with the global anxiety created by the presidency of Donald Trump.

So what is to be done, and how do we escape these endless cycles of anxiety creation and diffusion? How to unlock the progressive and the creative? We see this symposium as an opportunity to discuss what conceptual possibilities are being opened through the promise of emancipation. The symposium raises several ethicalpolitical points around the emancipatory promise of anxiety.

The first one is that anxiety does not have to be necessarily regressive, as established already by existentialists. Rumelili points to how anxiety can also be emancipatory and self-actualising by liberating society from the present institutions and identities. She reminds us that anxiety can initiate peace processes as it disturbs identities rooted in violent routines and securitised self/other images. Drawing on Søren Kierkegaard, Paul Tillich and Rollo May, Karl Gustafsson shifts our attention to anxiety as stemming from creativity and our freedom to bring something new into being. While Rumelili sees anxiety as a precondition for emancipation, for Gustaffson via Kierkegaard and others, it is a reaction to our freedom. In contrast to Rumelili and Gustaffson, Steele is more pessimistic. In his 
analysis of the US, the measures adopted to placate anxiety during covid-19 only generated more anxiety, tearing 'through a polity like a hot knife through butter'.

The second point is related to conditions under which anxiety can have emancipatory effects. Zevnik, for instance, argues that in contrast to anxiety that stems from too little authority, which usually leads to authoritarian backsliding, too much authority leads to fantasies of freedom. But if anxiety carries this creative possibility, why then does it usually lead to populist securitisation, deepening of antagonisms and conflict? Why does world politics allow so little space for the 'courage to be', to use the term coined by Tillich, to face anxiety, leave the cycle of violence and create new patterns and fundamentally new relationships? According to Gustafsson, it is so because novel ideas are usually seen as threatening, while familiar ideas are easier to accept because they provide a sense of calm. The solution he proposes is perseverance to turn the new into normal and familiar.

The ongoing global pandemic has not only threatened our lives and revealed the fragility of our health systems, but it has also ruptured our daily routines and created a great deal of uncertainty about the future. It multiplied anxieties that had already been in place and created new ones globally and with intensity unprecedented since the world wars of the last century. By unpacking the relationships between anxiety, moods, ethics and emancipation, this symposium aims to set the stage for an interdisciplinary dialogue that can-if not solve our political anxiety-then at least help us understand it, manage it, and use it productively. The title of this introduction suggests a turn to existentialism, even though we are fully aware that our constantly spinning IR community is certainly already dizzy enough with many different 'turns' suggested lately. However, we hope that the turn to existentialism can help us better understand and hopefully teach us how to live with the ever-growing dizziness stemming from our perpetually accelerating age of anxiety.

\section{References}

Berenskötter, Felix (2021) 'Anxiety and the Biographical Gestalt of Political Leaders', Journal of International Relations and Development, https://doi.org/10.1057/s41268-021-00225-z.

Gustafsson, Karl (2021) 'Why is Anxiety's Positive Potential so Rarely Realised? Creativity and Change in International Politics', Journal of International Relations and Development, https://doi.org/10. 1057/s41268-021-00224-0.

Rumelili, Bahar (2021) '[Our] Age of Anxiety: Existentialism and the Current State of International Relations', Journal of International Relations and Development, https://doi.org/10.1057/ s41268-021-00226-y.

Steele, Brent (2021) 'Nowhere to Run to, Nowhere to Hide: Inescapable Dread in the 2020s', Journal of International Relations and Development.

Zevnik, Andreja (2021). 'Anxiety, Subjectivity and the Possibility of Emancipatory Politics', Journal of International Relations and Development, https://doi.org/10.1057/s41268-021-00221-3.

Publisher's Note Springer Nature remains neutral with regard to jurisdictional claims in published maps and institutional affiliations. 
Jelena Subotić is a Professor at the Department of Political Science, Georgia State University. She writes broadly about international relations theory, memory politics, human rights, transitional justice, international ethics, state identity, and the politics of the Western Balkans. Her new book, Yellow Star, Red Star: Holocaust Remembrance after Communism, was published by Cornell University Press in 2019.

Filip Ejdus is an Associate Professor of Security Studies at the University of Belgrade, Faculty of Political Science. In his research he investigates management of (in)security during crises and beyond borders with a geographic focus on the Western Balkans, the European Union, the Middle East and the Horn of Africa. His most recent book is entitled Crisis and Ontological Insecurity: Serbia's Anxiety over Kosovo's Secession (Palgrave Macmillan, 2019). He is closely involved with policy community as the president of the board of the Belgrade Centre for Security Policy, academic coordinator at the Belgrade Security Forum and co-chair of the Regional Stability in South East Europe Study Group at the PfP Consortium of Defence Academies and Security Studies Institutes. 